NBER WORKING PAPER SERIES

\title{
GROWTH EFFECTS OF INCOME \\ AND CONSUMPTION TAXES: POSITTVE \\ AND NORMATIVE ANALYSIS
}

Gian Maria Milesi-Ferretti

Nouriel Roubini

Working Paper 5317

\author{
NATIONAL BUREAU OF ECONOMIC RESEARCH \\ 1050 Massachusetts Avenue \\ Cambridge, MA 02138 \\ October 1995
}

We are grateful to Michael Devereux, Enrique Mendoza, Sergio Rebelo, and Howell Zee for helpful discussions. The opinions expressed reflect those of the authors and not of the International Monetary Fund, or the National Bureau of Economic Research. This paper is part of NBER's research programs in Public Economics, and International Finance and Macroeconomics.

(c) 1995 by Gian Maria Milesi-Ferretti and Nouriel Roubini. All rights reserved. Short sections of text, not to exceed two paragraphs, may be quoted without explicit permission provided that full credit, including ( $)$ notice, is given to the source. 


\title{
GROWTH EFFECTS OF INCOME \\ AND CONSUMPTION TAXES: POSITIVE \\ AND NORMATIVE ANALYSIS
}

\begin{abstract}
The effects of income and consumption taxation are examined in the context of models in which the growth process is driven by the accumulation of human and physical capital. The different channels through which these taxes affect economic growth are discussed, and it is shown that in general the taxation of factor incomes (human and physical capital) is growthreducing. The effects of consumption taxation on growth depend crucially on the elasticity of labor supply, and therefore on the specification of the leisure activity. The paper also derives implications for the optimal intertemporal choice of tax instruments.
\end{abstract}

Gian Maria Milesi-Ferretti

Research Department

International Monetary Fund

700 19th Street, NW

Washington, DC 20431
Nouriel Roubini

Department of Economics, MEC 7-83

Stern School of Business

New York University

44 West 4th Street

New York, NY 10012-1126

and NBER 


\section{INTRODUCTION}

The debate on the relative merits of consumption versus income taxation has a long intellectual history, dating back at least to Hobbes (1651). The relative merits of a shift from current tax systems based on personal income taxation to one based on an expenditure tax are at the center of policy debates on tax reform in the US and elsewhere. According to its proponents, an expenditure tax would eliminate the bias against savings inherent in a system based on income taxes, known as "double taxation of savings". Eliminating this bias would encourage capital accumulation, thus raising future living standards. It is therefore interesting to explore the growth and welfare implications of income and expenditure (consumption) taxes in the standard models used to study accumulation and long-run growth.

This paper presents a positive and normative analysis of the effects of consumption taxation relative to income taxation in models of endogenous growth. In these models economic growth is driven by private agents' accumulation of physical capital in the production sector and of human capital in the education sector. This framework is particularly appropriate for the study of long-run economic efficiency; it cannot, however, address inter- and intra-generational distribution issues because it assumes the existence of a representative agent or "dynasty" with an infinite horizon.

In previous work (Milesi-Ferretti and Roubini (1994) we considered the effects of income taxes in growth models. We showed that in a wide class of endogenous growth models, both labor (human capital) income taxes and physical capital income taxes have negative growth effects; furthermore, a formal intertemporal optimal taxation analysis implies that, in the absence of constraints to the government's ability to borrow, the optimal long-run tax rates on both labor and capital income are zero. These results generalize to a wider class of growth models, those obtained by Jones, Manuelli and Rossi (1993a, b) and Bull (1993) for the case where leisure is defined as 'raw time'. The implications for the optimal taxation of factor incomes in all these endogenous growth models differ from the traditional Chamley-Judd result about the optimality of long-run zero taxation of capital income and positive taxation of labor income in neoclassical exogenous growth models. 
In the present paper we introduce in the analysis consumption taxes in addition to labor and capital income taxes, consider their impact on economic growth, and derive some implications for the optimal taxation of factor incomes and consumption. The positive effects of consumption taxes in models of endogenous growth have been studied in a number of recent contributions, including Rebelo (1991), Pecorino (1993), Devereux and Love (1994), and Stokey and Rebelo (1995). For what concerns the optimal taxation of consumption versus income, the only results in the literature are those of Jones, Manuelli and Rossi (1993b) and Bull (1993) who show that all optimal taxes (on labor, capital and consumption) should be set to zero in the long run.

Here we generalize the results of these previous contributions in a number of directions. First, we consider a more general setup that allows for different specifications of the leisure function and for alternative specifications of the human capital accumulation equation. Specifically, we consider different formulations of the leisure activity, such as raw time, quality time and home production. Moreover, we consider two alternative specifications for the human capital accumulation equation, one in which only labor inputs enter in the production of human capital and the other where physical capital inputs are additional inputs in such production function. Second, we analyze how the effects of taxation on growth depend on the specification of leisure, the structure of the human capital accumulation sector and its tax treatment. Third, we present a systematic analysis of the optimal taxation of consumption and factor incomes in the alternative classes of endogenous growth models that we are considering.

The structure of the paper is as follows. Section 2 presents a survey of the debate on the relative merits of consumption versus capital and labor income taxation. Section 3 presents the model, and section 4 solves for the competitive equilibrium. The positive analysis of the effects of different taxes on the growth rate of the economy is presented in section 5; section 6 presents the results of the optimal taxation analysis. Section 7 discusses quantitative and empirical aspects, and Section 8 concludes. 


\section{SURVEY OF THE LITERATURE}

An early argument for the superiority of consumption taxes over income taxes was formulated by Hobbes (1651). He compared the burdens on a worker who "laboureth much, and sparing the fruits of his labor" with that of an individual who "liveth idley and spendeth all he gets". John Stuart Mill and, in more recent time, Kaldor (1955) have presented arguments in favor of consumption taxes relative to income taxes. ${ }^{1}$ Mill's concern, in particular, was with the double taxation of savings implicit in an income tax, a double taxation that a consumption tax avoids. However, what should matter is not how often one is taxed but rather how heavily one is taxed. An income tax leads to a heavier taxation of deferred (future) consumption relative to current consumption. Conversely, an consumption tax that is uniform over time imposes the same burden on current and future consumption. Therefore the choice between consumption and income taxation can be expressed as a question over the optimal rates of taxation of present and future consumption. In a traditional public finance approach, this question has been analyzed in terms of the relative substitutability of consumption and leisure at different points in time. Since leisure is an untaxed factor, standard optimal taxation principles imply that one should tax more heavily goods that are more complementary and/or less substitutable with leisure (see Slemrod (1990), Stern (1992) and Kay (1989)). It should also be observed that since a uniform consumption tax is equivalent to a wage tax in a setup where the labor supply is exogenous, i.e. when there is no leisure (see Slemrod (1990)), the issue can be rephrased as one of the relative optimality of a consumption (wage) tax compared to a capital income tax. In general, uniform consumption taxation will be superior to income taxation if the utility function is separable between consumption and leisure, and preference are homothetic over consumption at different dates (Kay (1989)). However, as discussed by Stern (1992), King (1980), Atkinson and Sadmo (1980) and Auerbach, Kotlikoff and Skinner (1983), the above result is not very general and breaks down when consumption and leisure are not separable and/or if agents

\footnotetext{
${ }^{1}$ See Kay (1989) for a good historical survey of this debate.
} 
work more than one period.

A more recent literature has addressed the question of the relative optimality of consumption versus income taxation in the context of growth models where capital income taxation affects the savings and investment rate of the economy. Feldstein (1978) and Boskin (1978) argued that the taxation of capital income would affect the accumulation of capital, the long run capital-labor ratio and therefore the long-run per-capita level of income. These effects of different types of taxes on the capital stock of the economy were argued to be more important, in welfare terms, than the intertemporal distortion of lifetime consumption decisions stressed by the traditional static public finance literature. Specifically, Feldstein (1978) made the point that capital income was taxed excessively, given sensible assumptions about the elasticity of savings with respect to the after tax interest rate. He showed that large efficiency gains would be obtained by eliminating the capital income tax and replacing it with a labor income tax. King (1980) then argued that Feldstein's analysis implied that a consumption tax would be optimal.

Summers (1981) formalized the intuition of Feldstein and Boskin by considering an optimal growth model with endogenous savings decisions. He argued that if the intertemporal elasticity of substitution is high and the time horizon of the agent is very long, the savings rate will be very sensitive to its real return and a change in capital income taxes would have a very strong effect on the accumulation of capital and the long run capital-labor ratio in the economy. Numerical simulations presented by Summers suggested that replacing income taxes with consumption taxes would lead to a $18 \%$ increase in steady state income as the high interest elasticity of savings leads to a large increase in the long-run capital-labor ratio.

Next, Chamley (1986) presented an optimal dynamic taxation analysis of this issue in a optimizing infinite horizon model and showed that when the tax instruments available are a capital income tax and a labor income tax, the optimal long run tax on capital income is zero while it is positive for labor 
income. $^{2}$ The same result is obtained when a labor income tax is replaced by a consumption tax.

Simulation results from OLG general equilibrium models (see Auerbach, Kotlikoff and Skinner (1983), Fullerton, Shoven and Whalley (1983) and Auerbach and Kotlikoff (1987)) confirmed the benefits of switching from an income tax to a consumption tax (or a labor income tax). These studies showed that such a tax policy reform would lead to average welfare gains of the order of two percentage points of income. In all cases the effects derived from the strong response of savings and capital accumulation to a change in the net return to capital.

More recently, the study of the interaction between tax policy and economic growth has been stimulated by the development of the "new" growth theory, that uses models in which the rate of growth of the economy is determined endogenously. Several authors have used these models to study both positive and normative aspects of tax policy. Papers by Lucas (1990), King and Rebelo (1990), Kim (1992), Jones et al. (1993a), Pecorino (1993), Devereux and Love (1994), and Stokey and Rebelo (1995) among others use simulations in order to quantify growth and welfare effects of tax reforms, such as, for example, a shift from income to consumption taxes or a lowering of capital income taxes. Although the quantitative growth and welfare effects identified by these studies differ considerably, they all point out that consumption taxation induces fewer distortions than capital and labor income taxation. Optimal taxation analysis by Jones, Manuelli and Rossi (1993b), and Bull (1993) shows that the optimal long-run values of all distortionary taxes (including the consumption tax) are zero when there is no restriction on the government's intertemporal borrowing and lending decisions and leisure is modeled as "raw time". In these papers, consumption and income taxes have different long-run growth and welfare effects (the growth effects of consumption taxes being in general less strong). We turn now to our model, postponing until Section 7 a more complete discussion of quantitative findings and empirical evidence.

\footnotetext{
2 Judd $(1985,1987)$ confirmed the robustness of Chamley's results when the population is heterogenous.
} 


\section{THE MODEL}

We consider a three-sector economy. The first sector produces final goods (and physical capital); the second produces human capital and the third produces a non-market good -- a leisure activity that can take the form of "home production" or "quality time".

\subsection{Technology}

Physical output is produced with a constant returns to scale (CRS) technology that uses human capital $H$ and physical capital $K$ as inputs. The technology is assumed to take the Cobb-Douglas form:

$$
Y_{t}=A\left(\nu_{t} K_{t}\right)^{\alpha}\left(u_{t} H_{t}\right)^{1-\alpha}
$$

where $v(u)$ is the fraction of physical (human) capital devoted to the production of goods. The capital stock is assumed to depreciate at the rate $\delta$.

Human capital is a non-market activity. ${ }^{4}$ It is produced with a CRS technology that uses both human and physical capital as inputs, as in Rebelo (1991). It depreciates at a rate $\delta$, equal for simplicity to the rate of depreciation of physical capital..$^{5}$ The production function is assumed to be Cobb-Douglas as well: ${ }^{6}$

$$
H_{t}=B\left(x_{t} K_{t}\right)^{\beta}\left(z_{t} H_{t}\right)^{1-\beta}-\delta H_{t}
$$

where $x(z)$ is the fraction of physical (human) capital devoted to the accumulation of human capital. In

${ }^{3}$ The specification of the first two sectors is similar to Rebelo (1991), Mulligan and Sala-i-Martin (1993) and Caballé and Santos (1993).

${ }^{4}$ For a discussion of the case in which human capital is a market activity, see Section 4.3.

${ }^{5}$ This assumption allows the derivation of a simple closed-form solution for the growth rate, but does not affect the qualitative nature of the results.

- Our results generalize to the case in which the technologies are CRS with positive cross-derivatives. See Rebelo (1991) and Jones, Manuelli and Rossi (1993b). 
equations (1) and (2) we have implicitly assumed that the "point-in-time technologies" are linear: if a fraction $v$ of the capital stock is employed in the production of final goods, the "effective capital" is $v K$. This assumption is not necessary for our results: the crucial assumption is that there are CRS in physical and human capital, the reproducible factors. ${ }^{7}$

\subsection{The government}

The government needs to finance an exogenously given path of public expenditure, using factor income taxation and bonds. Without loss of generality, we assume that government bonds are taxexempt. The instantaneous budget constraint faced by the government is given by:

$$
B_{1}=r_{1} B_{1}+G_{1}-T_{t}
$$

where $B_{t}$ are government bonds, $r_{t}$ is their rate of interest and $T_{t}$ is total tax revenue. The usual no Ponzi game condition applies. In every period, the resource constraint of the economy is given by:

$$
K_{t}=Y_{t}-\delta K_{t}-C_{t}-G_{t}
$$

where $C$ is private consumption and $G$ is government expenditure.

\subsection{Private agents}

The economy is inhabited by identical atomistic agents. They operate the human capital accumulation technology described in equation (2) and they rent human and physical capital to firms. Consumption, investment and the allocation of human and physical capital are chosen with the purpose of maximizing an intertemporal utility function:

$$
U=\int_{0}^{\infty} e^{-\rho t} u\left(C_{t}, l_{t}, L_{t}\right) d t
$$

\footnotetext{
${ }^{7}$ Mulligan and Sala-i-Martin (1993) discuss more in detail the role of the point-in-time technologies.
} 
where $\rho$ is the rate of time preference, $l$ is leisure time and $L$ is "leisure activity", that could include for example home production. We assume that the instantaneous utility function takes a Constant Intertemporal Elasticity of Substitution (CIES) form:

$$
\begin{array}{ll}
u\left(C_{t}, l_{t}, L_{t}\right)=\frac{\left(C_{t} l_{t}^{t} L_{t}^{\eta}\right)^{1-\theta}}{1-\theta}-1 & \theta \neq 1 \\
u\left(C_{t}, l_{t}, L_{t}\right)=\log C_{t}+\epsilon \log l_{t}+\eta \log L_{t} & \theta=1
\end{array}
$$

where $\theta$ is the inverse of the intertemporal elasticity of substitution. ${ }^{8}$ The utility function is similar to the one in Benhabib, Rogerson and Wright (1991), and its functional form has been shown to be consistent with the existence of a balanced growth path by King et al. (1988). When $\eta=0$, we have a standard formulation of the utility function in which leisure is "raw time", as in most endogenous growth models with leisure (Lucas 1990, Jones et al., 1993a, 1993b, Bull 1993).

Consumers' utility maximization is subject to the constraint on human capital accumulation given by (2) and to the consumer's budget constraint:

$$
R_{t}^{K}\left(1-\tau_{t}^{K}\right) v_{t} K_{t}+R_{t}^{H}\left(1-\tau_{t}^{H}\right) u_{t} H_{t}+r_{t} B_{t}-C_{t}\left(1+\tau_{t}^{C}\right)-B_{t}-K_{t}-\delta K_{t} \geq 0
$$

where $R^{K}, R^{H}, \tau^{K}$ and $\tau^{H}$ are the rates of return and the tax rates on capital and labor income, respectively, and $\tau^{C}$ is a consumption tax. Clearly total tax revenues $T$ are equal to $\tau^{K} R^{K} v K+\tau^{H} R^{H} u H+\tau^{C} C$. If human capital accumulation was a market activity, the returns on physical and human capital employed in that sector would appear in the budget constraint with a positive sign, while the amount of human capital investment (the first term on the RHS of (2)) times its relative price would appear with a negative

${ }^{8}$ The qualitative nature of our results would be unchanged if we adopted the more general specification:

$$
U(C, L, l)=(1-\theta)^{-1}\left[\left(\frac{C^{\pi}+\eta L^{\pi}}{1+\eta}\right)^{\frac{1+\eta}{\pi}} l^{\epsilon}\right]^{1-\theta}-1
$$

which reduces to (9) for $\pi=0$. 
sign.

The leisure activity ("home production") uses human and physical capital as inputs, with a CobbDouglas technology:

$$
L_{t}=\left[\left(1-v_{t}-x_{t}\right) K_{t}\right]^{\phi}\left(w_{t} H_{t}\right)^{1-\phi}
$$

where $w$ is the fraction of time devoted to "home production". Each individual's time endowment is normalized to one:

$$
l_{t}+u_{t}+w_{t}+z_{t}=1
$$

When $\epsilon=0$ and $\eta>0$, leisure is equivalent to a form of "home production", as in Greenwood and Hercowitz (1991). A special case of this occurs when $\phi=0$, so that leisure is "quality time", as in Becker (1965), Heckman (1976) and Rebelo (1991).

\subsection{Firms}

Firms rent capital from households at the rate of interest $R^{R}$ and hire labor at the wage rate $R^{H}$. They use these factors to produce goods with the technology described by equation (1). They hire labor and capital up to the point at which their marginal product equates their marginal cost:

$$
\begin{gathered}
R_{t}^{K}=\alpha A\left[\frac{v_{t} K_{t}}{u_{t} H_{t}}\right]^{\alpha-1} \\
R_{t}^{H}=(1-\alpha) A\left[\frac{v_{t} K_{t}}{u_{t} H_{t}}\right]^{\alpha}
\end{gathered}
$$

If human capital was a market activity, a similar set of conditions would apply for the wage and rental rates in that sector. 


\section{THE COMPETITIVE EQUILIBRIUM}

The representative consumer takes the paths of $R^{H}, R^{K}, \tau^{K}, \tau^{H}$ and $\tau^{C}$ as given and chooses the paths of $C, B, K, H, l, u, v, x, w, z$ to maximize (5) subject to (2) and (7).

\subsection{Leisure as "raw time"}

We first consider the case in which there is no "home production", so that leisure consists of "raw time" only. Analytically, this implies $\eta=0$, so that $w=0, l=1-u-z$ (by eq.(9)) and $x=1-v$. We will consider next the model with home production $(\epsilon=0, \eta>0)$. We can define non-human wealth $W_{t}=K_{t}+B_{t}$, and re-write (6) as follows:

$$
r_{t} W_{t}-\left[r_{t}+\delta-R_{t}^{K}\left(1-\tau_{t}^{K}\right) v_{t}\right] K_{t}+R_{t}^{H}\left(1-\tau_{t}^{H}\right) u_{t} H_{t}-C_{t}\left(1+\tau_{t}^{C}\right) \geq W_{t}
$$

The first-order conditions with respect to $C, W, K, H, u, v$ and $z$ respectively are presented in the Appendix. This economy will exhibit a balanced growth path, along which consumption, physical capital and human capital grow at the same rate $\gamma$, while factor allocations $(u, v$, and $z)$ remain constant. ${ }^{9}$ The equilibrium conditions along the balanced growth path are given by:

$$
\begin{gathered}
\gamma=\frac{1}{\theta}(r-\rho) \\
r=(1-\beta) B\left[\frac{(1-v) K}{z H}\right]^{\beta}(u+z)-\delta \\
r=\left(1-\tau^{\boldsymbol{K}}\right) \alpha A\left[\frac{v K}{u H}\right]^{\alpha-1}-\delta
\end{gathered}
$$

\footnotetext{
${ }^{9}$ Mulligan and Sala-i-Martin (1993) and Barro and Sala-i-Martin (1994) give the necessary conditions for the existence of a balanced growth path.
} 


$$
\begin{gathered}
\frac{v}{u}=\frac{\alpha}{1-\alpha} \frac{1-\beta}{\beta} \frac{1-\tau^{K}}{1-\tau^{H}} \frac{1-v}{z} \\
\gamma=B z\left[\frac{(1-v) K}{z H}\right]^{\beta}-\delta \\
\frac{C}{Y}=\frac{1-\tau^{H}}{1+\tau^{C}} \frac{1-u-z}{u} \frac{1-\alpha}{\epsilon} \\
\frac{C}{Y}+\frac{1}{A v}\left[\frac{v K}{u H}\right]^{1-\alpha}(\gamma+\delta)=1-\frac{G}{Y}
\end{gathered}
$$

Equation (13) links the growth rate with the net rate of return on capital and with the elasticity of intertemporal substitution. Equation (14) defines $r$, and equation (15) establishes the equality in rates of return between the sector producing goods and the one producing human capital. Equation (16) is derived from the equality in the rates of return on physical and human capital in the two sectors. Equation (17) describes equilibrium in the human capital accumulation process -- human capital grows at the same rate as consumption and physical capital. Equation (18) is derived from the equal ity between the marginal rate of substitution between consumption and leisure and the real rate of return on human capital. Finally, equation (19) is the resource constraint for the economy, where all variables are expressed as a fraction of physical capital. The system of equations (13)-(19) can be solved for the values of $\gamma, r, K / H, C / Y, u$, $v$ and $z$ as a function of technology parameters and of the exogenous fiscal variables $\tau^{C}, \tau^{H}, \tau^{K}$ and $G / Y$. From equations (13)-(16), we obtain the following semi-reduced expression for the growth rate:

$$
\gamma=\frac{1}{\theta}\left\{\left[D\left(1-\tau^{K}\right)^{\alpha \beta}\left(1-\tau^{H}\right)^{\beta(1-\alpha)}(u+z)^{1-\alpha}\right]^{\frac{1}{1-\alpha+\beta}}-\rho-\delta\right\}
$$

where $D=(\alpha A)^{\beta}[B(1-\beta)]^{1-\alpha}[(1-\alpha) \beta / \alpha(1-\beta)]^{\beta(1-\alpha)}$ is a function of the technology parameters $\alpha, \beta, A$ and B. 


\subsection{Human capital as a market good}

This is the case considered by Pecorino (1993) and Stokey and Rebelo (1995). ${ }^{10}$ Assume for simplicity that factor income tax rates are independent of whether the factor is employed in the human capital or final goods sector. Clearly, the rates of return on human and physical capital have to be the same in both sectors. With respect to the case considered in the previous sub-section, the equation determining the rate of return on human capital (equation (15)) will now be calculated net of the labor tax rate (that is, multiplied by $\left.1-\tau^{H}\right)$ :

$$
r=(1-\beta) B\left(1-\tau^{H}\right)\left[\frac{(1-v) K}{z H}\right]^{\beta}(u+z)-\delta
$$

Furthermore, the equation relating the capital/labor ratios in the two sectors (equation (19)) will be independent of tax rates, so that

$$
\frac{v}{u}=\frac{\alpha}{1-\alpha} \frac{1-\beta}{\beta} \frac{1-v}{z}
$$

In this case, the semi-reduced form for the growth rate can be expressed as follows:

$$
\gamma=\frac{1}{\theta}\left(D\left[\left(1-\tau^{K}\right)^{\beta}\left(1-\tau^{H}\right)^{1-\alpha}(u+z)^{1-\alpha}\right]^{\frac{1}{1-\alpha+\beta}}-\delta-\rho\right)
$$

Note that if the physical capital employed in education were to be untaxed (for example, because educational institutions have non-profit status) the exponent on the capital income tax in equation (21) would be the same as in equation (20): that is, $\alpha \beta$.

\subsection{The model with "home production"}

Evaluating the first-order conditions for the "home production" model $(\epsilon=0, \eta>0)$ along the

${ }^{10}$ They also assume that physical capital and consumption goods are produced in different sectors. This assumption, however, has no bearing on the effects of tax rates on economic growth. 
balanced growth path we obtain a set of equilibrium conditions similar to those derived above, with $x$ replacing $(1-v)$. There are, however, a few differences. The equation relating the rate of growth to the net rate of return on capital is now:

$$
\gamma=\frac{1}{\theta-\eta(1-\theta)}(r-\rho)
$$

The marginal product in the human capital equation is now given by:

$$
r=(1-\beta) B\left[\frac{x_{t} K_{t}}{z_{t} H_{t}}\right]^{\beta}-\delta
$$

The equality between the marginal rate of substitution between consumption and leisure and the real wage is now:

$$
\frac{C}{Y}=\frac{1-\tau^{H}}{1+\tau^{C}} \frac{1-u-z}{u} \frac{1-\alpha}{\eta(1-\phi)}
$$

If leisure is modeled as "quality time" $(\phi=0)$, these would be the equilibrium conditions. If leisure is "home production", there is an additional equilibrium condition reflecting the optimal allocation of physical capital between production of consumption goods and of leisure:

$$
\frac{v}{u}=\frac{\alpha}{1-\alpha} \frac{1-\phi}{\phi} \frac{1-\tau^{K}}{1-\tau^{H}} \frac{1-v-x}{1-u-z}
$$

Solving for $\gamma$ the system formed by equations (13"), (14), (15") and (16) (with $x$ replacing $1-v$ for the case in which leisure is home production) we obtain the following reduced-form expression for the growth rate:

$$
\gamma=\frac{1}{\theta-\eta(1-\theta)}\left(\left[D\left(1-\tau^{K}\right)^{\alpha \beta}\left(1-\tau^{H}\right)^{(1-\alpha) \beta}\right]^{\frac{1}{1-\alpha+\beta}}-\delta-\rho\right)
$$




\section{TAXATION AND LONG-RUN GROWTH}

In this section we discuss the channels through which taxes affect growth in the class of models we are considering, and then state some formal propositions. We take as benchmark the "leisure as raw time" model, and highlight the differences with alternative model specifications.

Inspection of the system of equations (13)-(19) and of the semi-reduced expression for the growth rate given by (20) reveals that in general all three tax rates will have an effect on the long-run growth rate of the economy. The channels through which each tax affects long-run growth can be summarized as follows:

\section{1) Tax on Physical Capital}

K.i) it reduces the net-of-tax real interest rate $r$, for a given capital/labor ratio in production $v K / u H$ (see equation (14)). This has a negative effect on growth.

K.ii) it reduces the capital/labor ratio in production $(v K / u H)$ for a given allocation of time between work and leisure, thus increasing the gross-of-tax return on capital (equations (14)-(16)).

This has a positive effect on growth, which is not greater than the negative effect K.i (see equation (20)).

K.iii) It affects the work (labor/education) - leisure decision $(u+z)$, which in turn affects the capital/labor ratio in production (equations (14)-(16)). The effect on growth depends on parameter values, but is negative if the elasticity of intertemporal substitution $1 / \theta$ is sufficiently high. ${ }^{11}$

Irrespectively of the value of $\theta, \mathrm{K} . \mathrm{i}+\mathrm{K} . \mathrm{ii}+\mathrm{K}$.iii $<0$ : that is, the overall effect of a capital income

"See the Appendix for a sketch of the formal proof, which is constructed along the lines of Devereux and Love (1994). The intuitive argument goes as follows. For a given growth rate, a higher capital income tax rate reduce the incentive to work and therefore reduce $u+z$. However, it also reduces the growth rate, thereby encouraging substitution of work for leisure (a form of wealth effect). If $\theta$ is low, the first effect dominates. 
tax on growth is negative, as pointed out by Devereux and Love (1994). ${ }^{12}$

\section{2) Tax on Human Capital:}

$\mathrm{H} . \mathrm{i})$ it raises the capital/labor ratio in production $(v K / u H)$ for a given allocation of time between work and leisure, thus reducing the gross-of-tax return on capital (equations (14)-(16)). This has a negative effect on growth.

H.ii) It affects the labor/education - leisure decision $(u+z)$, which in turn affects the capital/labor ratio in production (equations (14)-(16)). The effect on growth depends on parameter values, but is negative if the elasticity of intertemporal substitution $1 / \theta$ is sufficiently high or $\beta$ sufficiently low (see footnote 12 ).

Irrespectively of the value of $\theta, \mathrm{H} . \mathrm{i}+\mathrm{H} . \mathrm{ii}<0$ : that is, the overall effect of a capital income tax on growth is negative.

3) Tax on Consumption:

C.i) It affects the labor/education - leisure decision $(u+z)$, which in turn affects the capital/labor ratio in production (equations (14)-(16) and (18)-(19)). The effect on growth is negative.$^{13}$

Modifications of the "raw time" model presented in Section 2.1 would alter the effects of taxes on growth through some or all of these channels. Consider, for example, the following cases:

a) No leisure $(\epsilon=0$ ). In this case, $u+z=1$, and therefore equation (20) now gives a closed-form

\footnotetext{
${ }^{12}$ See the Appendix for a formal proof.

${ }^{13}$ See the Appendix for a formal proof.
} 
expression for the growth rate (see, for example, Rebelo (1991)). The implications for growth are as follows:

a1) $\mathrm{K} . \mathrm{iii}=\mathrm{H} . \mathrm{ii}=\mathrm{C} . \mathrm{i}=0$ (a consumption tax has no growth effects);

If, in addition, $\beta=0$,

a2) $\mathrm{K} . \mathrm{i}+\mathrm{K} . \mathrm{ii}=\mathbf{0}, \mathrm{H} . \mathrm{i}=\mathbf{0}$ (all taxes have no growth effects).

b) Leisure is raw time $(\epsilon>0)$ and physical capital does not enter in the production of $H(\beta=0)$. This is the case considered in Lucas (1990). The implications are:

b1) $H . i=0$ (a tax on human capital affects growth only through its impact on the work/leisure decision).

b2) H.ii = C.i (a tax on human capital is perfectly analogous to a consumption tax).

c) Leisure is raw time $(\epsilon>0)$ and human capital is produced in a "market" sector, whose returns are taxed (Section 4.2). All channels identified earlier will be operative. However, if $\beta=0$,

c1) $\mathrm{K} . \mathrm{i}+\mathrm{K} . \mathrm{ii}=0$

That is, a tax on capital income will affect the growth rate only through its effect on the work/leisure decision, analogously to the consumption tax (see equation (21)). By contrast, a labor income tax will reduce economic growth also through its effect on the capital/labor ratio in the production of physical capital, or, equivalently, through its direct effect on the rate of return in the human capital sector.

d) Leisure is quality time/home production (CRS in $H$ and/or $K$-- Section 4.3). In this case the term $u$ $+z$ does not appear in the equation for the rate of return on human capital (equation $\left(15^{\prime \prime}\right)$ ), and the system can be solved recursively as in case a) (see Milesi-Ferretti and Roubini (1994)). More precisely,

d1) $\mathrm{K}$. iii $=\mathrm{H} . \mathrm{ii}=\mathrm{C} . \mathrm{i}=\mathbf{0}$ (a consumption tax has no growth effects); 
If in addition $\beta=0$,

d2) $K . i+K . i i=0, H . i=0$ (all taxes have no growth effects).

Therefore, factor income taxes are growth reducing in most endogenous growth models; whether a consumption tax is also growth reducing depends on the specification of the leisure activity. The effect of taxes on human and physical capital on growth in models where there is no leisure or where leisure is CRS in reproducible factors are proportional to the parameter $\beta$, the share of physical capital in the production of human capital, provided that the education sector is not taxed (the limiting case being no effects on growth if $\beta=0$ ).

We now state the main results more formally. The first two propositions restate results derived in Milesi-Ferretti and Roubini (1994a) regarding the effects of factor income taxation on growth.

Proposition 1 If leisure is modeled as "raw time" the balanced growth rate of the economy always depends negatively on the tax rates on capital and labor income, regardless of whether $H$ is a market good and of its technology.

Proof Equations (20) and (21) show the direct effects of taxes on growth, for given time spent working or studying. Capital and labor taxes have additional indirect effects on growth through their impact on $u+z$. The Appendix sketches a proof that the overall growth effect is negative. $\|$

The intuition for the result can be more easily obtained by considering the case where $\beta=0$, in which case the growth rate can be expressed as $B z-\delta .{ }^{14}$ Consider the effects of an increase in the labor tax: while the relative cost of and return to working versus accumulating human capital are unchanged, the return to the leisure activity is increased with respect to the return to work since the time spent in leisure

\footnotetext{
14 See Rebelo (1991) for an explanation along the same lines.
} 
is untaxed. The ensuing increase in time spent in leisure reduces the time spent accumulating human capital and therefore its return. The reduction in the return to investment in human capital will then imply that the equilibrium real interest rate is reduced and therefore the rate of growth of the economy is reduced in the steady state. A similar argument can be made for the effects of changes in capital income taxes on growth, as well as to show that the growth rate depends on the two tax rates when $\beta$ is positive.

Proposition 2 In the home production model and its subcases (quality time and no leisure) the effects of factor income taxation on long-run growth depend on the human capital accumulation technology, provided that the human capital sector is tax-exempt. When physical capital does not enter in the production of human capital $(\beta=0)$, the balanced growth rate of the economy is independent of the tax rates on capital and labor income. When $\beta>0$, both factor income taxes reduce long-run growth.

Proof From equation (23), it is easy to see that the effects of factor income taxes on growth depends crucially on the size of the parameter $\beta$, and that they vanish when $\beta$ is equal to zero. In the latter case, the balanced growth rate of the economy is given by:

$$
\gamma=\frac{1}{\theta-\eta(1-\theta)}(B-\delta-\rho)
$$

which is independent of taxes. $\|$

The intuition for this result is simple. If human capital is produced with human capital only, an increase in the labor tax rate will reduce the return to current work effort but it will also reduce the return to human capital accumulation (and the return to the leisure activity) by the same amount. Therefore, the fraction of time spent studying -- which in this case determines the growth rate -- is unchanged. 
The intuition for the result when $\beta$ is positive is easier to present for the case of no leisure (but is the same in the equivalent cases of leisure as "quality time" or "home production"). We showed above that when $\beta=0$, the return to and the cost of human capital accumulation (i.e. the net of tax wage) are affected in the same proportion by a change in labor taxes, leaving the time allocation decision unchanged. In other terms, since the cost of human capital accumulation is effectively tax-deductible, labor income taxation does not affect the incentive to accumulate human capital. ${ }^{15}$ However, if physical capital is also used in the production of new human capital $(\beta>0)$, the return to human capital is reduced more than its cost. In particular, the cost of physical capital inputs used in the production of human capital is not reduced by the labor income tax since these inputs are not tax deductible. More generally, as suggested by Trostel (1993), if any other inputs in addition to human capital enter in the production of human capital, its return will be reduced by more than its cost. Therefore human capital accumulation will be reduced by an increase in the labor tax rate. ${ }^{16}$

Note that the real interest rate in the "quality time" and "home production" models of leisure is the same as in a model with no leisure $(\eta=0)$. This equivalence of "quality time" and "home production" models of leisure with the case of no leisure results from the fact that leisure is modeled as a non-market activity produced with constant returns to scale to reproducible factors. In these two cases, leisure can therefore be reinterpreted as a non-market consumption good and the model is substantially equivalent to one in which there is no leisure.

Finally, if human capital were a market sector, it is easy to show that a tax rate on human capital would be growth-reducing even when $\beta=0$, while in that case a capital income tax would still have no growth effects.

\footnotetext{
${ }^{15}$ See Trostel (1993) for a detailed presentation of this argument. It is clear that this line of reasoning would not be valid if human capital was produced in a "market" sector whose returns were taxed.

${ }^{16}$ See also Bull (1993a) and Jones, Manuelli and Rossi (1993b).
} 
Proposition 3 When leisure is "raw time", a consumption tax reduces long-run growth.

Proof Equation (20) shows that the growth rate depends on the fraction of leisure time. Inspection of the system of equations (13)-(19) reveals that both $u$ and $z$ are a function of $\tau^{c}$, and therefore $\gamma$ is a function of $\tau^{c}$. The Appendix proves that leisure time is increasing in $\tau^{c}$, and therefore growth is reduced.

The intuition for this proposition runs as follows. A consumption tax will alter the choice between work and education on the one hand and leisure on the other hand because of a substitution effect. Note, however, that there is no corresponding income effect because government spending is kept constant. An increase in a long-run tax rate implies an offsetting change in the net asset position of the private sector vis-à-vis the public sector along the transition path, so that the government's budget constraint is satisfied.

This argument explains the apparent contradiction between this result and the statement by Rebelo (1991) (in the context of a very similar model) that changes in consumption taxes have no growth effects. Rebelo considers a case in which government expenditure is determined endogenously by the total amount of tax revenue being collected, so that the additional tax revenues from an increase in the consumption tax are not rebated in a lump-sum fashion to consumers. In this case, discussed also in Stokey and Rebelo (1995), the income and substitution effects on the time spent working cancel out, so that the leisure choice is unaffected and changes in consumption taxes have no growth effects. This experiment is equivalent to a change in consumption taxes together with an increase in government spending. In the context of our model, Rebelo's result would obtain if we considered a change in consumption taxes leaving the net asset position of the private sector unchanged (so that public spending increases).

Proposition 4 A consumption tax has no effect on the long-run growth rate of the economy in the "home 
production" model and its subcases.

Proof See equation (23). \|

The intuition for this proposition is simple. In models where leisure is an activity produced with CRS in reproducible factors, the choice between labor and leisure does not affect long-run growth, because reducing physical and/or human capital accumulation in response to a consumption tax would reduce utility out of leisure.

There is a difference between the home production (or quality time) model and a model with no leisure. In the former, the consumption tax has an effect on the ratio of consumption to leisure and on the overall capital/labor ratio of the economy. In the latter, a consumption tax is equivalent to a lumpsum tax, since it does not affect any resource allocation decision. The difference between these models is quite logical -- the "home production" model is a model with two consumption goods, one of which is untaxed, and therefore a consumption tax involves a reallocation of resources across sectors. ${ }^{17}$

Proposition 5 When the leisure activity exhibits CRS in reproducible factors, the ratio between consumption and leisure along the balanced growth path is a negative function of all tax rates.

Proof Using equations (14), (15"), (18") and (22) the consumption-to-leisure ratio can be expressed as follows:

${ }^{17}$ If the output from "home production" could be subject to a consumption tax equal to that on market goods, the consumption tax would not affect equilibrium allocations and would therefore be equivalent to a lump-sum tax. 


$$
\frac{C}{L}=\left(1+\tau^{C}\right)^{-1}\left[D_{1}\left(1-\tau^{H}\right)^{(1-\gamma+\beta)(1-\alpha)}\left(1-\tau^{K}\right)^{1-\alpha \gamma+\beta}\right]^{\frac{1}{1-\alpha+\beta}}
$$

where $D_{I}$ is a function of technological parameters. Clearly, higher factor income tax rates and a higher consumption tax will all tend to shift consumption from "market" goods to "home production".

The intuition is very simple: when factor income taxes are positive, individuals will shift consumption to a non-taxed activity such as leisure. It is interesting to observe that one can rank the consumptionswitching effects of taxation: the elasticity of $C / L$ with respect to a capital income tax is the highest, followed by the elasticity with respect to a consumption tax and by the elasticity with respect to a labor income tax.

\section{OPTIMAL TAXATION ANALYSIS}

The previous section has highlighted the channels through which different taxes affect economic growth and resource allocation. In this section we study the tax policy that a benevolent social planner would choose in order to maximize the representative agent's welfare. This is known as a "Ramsey planner's problem" (Ramsey, 1927): at the beginning of time, the government irrevocably chooses the path of tax rates, taking into account how private agents respond to its choice of taxes.

There are two ways of studying this problem (see, for example, Lucas, 1990). The first involves the choice of taxes by the government so as to maximize the consumer's indirect utility function, subject to the first-order conditions of the consumer's maximization problem. This approach is followed, for example, by Chamley (1986). A different approach, based on Lucas and Stokey (1983) is also possible. This approach consists in formulating the government's problem as a restricted Ramsey planner problem, in which the government chooses quantities directly, subject to the consumer's intertemporal budget constraint and to the constraints related to the consumer's optimal allocation of human and physical 
capital. These constraints are derived from the FOCs of the consumer's problem; these, together with the firm's FOCs, are used to solve out for factor returns and taxes so as to express the problem in terms of quantities only. The optimal quantities chosen by the government will then implicitly determine tax rates and factor returns. This is the approach followed by Lucas (1990); Yuen (1990); Chari et al. (1991, 1994); Bull (1993), Jones et al. (1993a, b); Milesi-Ferretti and Roubini (1994) among others.

\subsection{Solution to the Ramsey planner's problem}

The optimal taxation problem we consider does not involve any constraint on the government's period-by-period budget, with the exception of the overall solvency constraint. In other words, the government is freely allowed to borrow and lend. We later discuss how the imposition of more restrictive constraints on government finances affects the nature of our results.

The optimal taxation problem, formally presented and solved in the Appendix, yields the following results: ${ }^{18}$

Proposition 6 In the "raw time" model of leisure, the optimal long-run tax rates on capital, labor and consumption are zero.

Proof See the Appendix. $\|$

Heuristically, the proof consists in guessing that all taxes are equal to zero along a balanced growth path, and then verify that this is a solution to the system of equations given by the first-order conditions and

\footnotetext{
${ }^{18}$ As other optimal taxation studies, our analysis does not prove formally existence and uniqueness of the optimal taxation plan.
} 
the constraints. ${ }^{19}$ The analysis of Chamley suggests that any tax that distorts a long-run intertemporal decision should be set equal to zero. In an endogenous growth framework, any tax distortion that reduces the long-run growth rate of the economy will have large and permanent costs (in terms of present discounted value of lost consumption and utility) and should therefore be set equal to zero. Since the balanced growth rate of the economy is dependent on all tax rates, it follows that all optimal taxes should be zero in the long run.

Proposition 7 In the "quality time" (and "home production") model the optimal tax rates on human capital, physical capital and consumption are zero in the long run.

Proof See the Appendix. \|

The intuition for the results for both factor income taxes are similar to those outlined above. When $\beta$ is positive, both taxes are growth-reducing and should therefore be set to zero in the long run. When $\beta$ is equal to zero, these taxes distort long-run growth and/or resource allocation and should therefore be set equal to zero. A consumption tax does not affect the economy's growth rate, but it affects the overall capital/labor ratio of the economy as well as consumption choices; hence it should also be set equal to zero in the long run.

There is an important difference between models where leisure is produced with CRS in reproducible factors and models in which there is no leisure. In the latter, a consumption tax is equivalent to a lump-sum tax, and would therefore be the only tax used in an optimal tax plan. Furthermore, if $\beta$ is equal to zero and leisure does not bring utility, a labor income tax is also non-distortionary.

19 See Bull (1993a) and Jones, Manuelli and Rossi (1993b) for a similar methodology. An immediate implication of this Proposition is that the optimal tax on labor income in the Lucas (1990) model is zero when the accumulation of human capital is endogenous. 
We do not study the complicated issue of optimal taxation along the transition to the balanced growth path. Clearly, when long-run taxes are zero, the government needs to accumulate budget surpluses in the short run in order to finance government expenditure with the accumulated assets in the long run. This suggests that the solution to the optimal taxation problem is characterized mainly by the time profile of taxation, featuring high taxation in the short run and no taxation in the long run, a point stressed by Jones et al. (1993b). Simulations by Jones et al. (1993a) show that reliance on the consumption tax during the transition is high. Simulations by Bull (1993) suggest that the transition period is relatively short.

The solution to the optimal taxation problem has the unrealistic feature that the government should accumulate budget surpluses in order to finance future government spending through the returns on its assets. This suggests that in order to derive policy implications from this analysis the optimal taxation problem should be formulated differently -- namely, by imposing restrictions on the government's ability to borrow and lend intertemporally. A limiting case of this is the imposition of a balanced budget period by period. To our knowledge, no formal analysis of this issue has been attempted. Pecorino (1993) and Milesi-Ferretti and Roubini (1994) have studied the growth-maximizing tax structure under a balanced budget. It should be noted that these exercises are normally conducted in cases in which labor supply is inelastic. This in general implies that a consumption tax has no growth effects, so that the analysis is restricted to the study of the optimal combination of human and physical capital taxation. For the more general case in which a consumption tax has growth effects, we speculate that the growth-maximizing tax structure would still feature heavy reliance on the consumption tax, given that it has growth effects only through the labor/leisure decisions while factor income taxes also affect directly accumulation decisions. The welfare-maximizing balanced-budget tax policy may have similar features.

\section{TAXES AND GROWTH: QUANTITATIVE ASPECTS}


As pointed out in Section II, several authors have studied the macroeconomic and welfare consequences of tax reforms by calibrating models so as to reflect features of real world economies (typically, the US). Lucas (1990), King and Rebelo (1990), Kim (1992), Jones, Manuelli and Rossi (1993a) and Pecorino (1993) consider the same policy experiment of a shift from capital income taxation to a consumption tax and/or labor tax in the context of endogenous growth models, obtaining substantially different growth and welfare effects. ${ }^{20}$ Stokey and Rebelo (1995) show that these different estimates depend on the models' structure and calibration, and argue that, although growth effects of tax reforms are likely to be modest, the welfare effects can be substantial because of the large reallocation of factors across sectors. Similar findings are reported by Devereux and Love (1994), who show that explicit consideration of transitional dynamics is important for the evaluation of the welfare consequences of tax reforms. They also provide an analytical characterization of these dynamics following a number of revenue-neutral tax changes, and show that increases in the capital income tax are more "costly" than increases in the labor income tax because they involve a large reduction in the capital/labor ratio as factors are shifted to the production of human capital.

In addition to the theoretical studies we have discussed so far, there have been a number of empirical studies that have examined the cross-country evidence on the effects of taxes on economic growth, such as Koester and Kormendi (1989), Engen and Skinner (1992) and Easterly and Rebelo (1993a, b). Although results differ from study to study, a common feature of their findings is that it is difficult to identify statistically significant effects of taxes on economic growth once other determinants of long-run growth are controlled for. Because of the difficulty in constructing measures of tax rates that are available for a sufficiently large number of countries and consistent across them, these empirical studies rely on aggregate measures of the tax burden, such as the ratio of tax revenue to GDP, as a proxy

\footnotetext{
${ }^{20}$ In these studies, the labor supply is either assumed to be exogenous or leisure is defined as 'raw time', i.e. time not spent in work or educational activities.
} 
for average effective tax rates, or on sums of statutory income tax rates or income tax returns weighted using income distribution data, as a proxy for aggregate marginal tax rates. These conventional tax measures are rough approximations of the tax variables defined in the models, and do not distinguish between different types of taxes. An exception is Mendoza, Milesi-Ferretti and Asea (1995) who study the effects of labor, capital and consumption taxes on private investment and growth in a panel of OECD countries, using tax measures constructed following the methodology developed by Mendoza, Razin and Tesar (1994). ${ }^{21}$ Their results are in line with those that theory and simulation exercises would lead to predict: factor income taxes tend to discourage private investment, but it is difficult to find statistically and economically significant effects of tax rates on growth.

\section{CONCLUDING REMARKS}

In this paper we examined the macroeconomic effects of consumption and factor income taxation on resource allocation, economic growth and welfare, and considered their implications for optimal taxation. In particular, we have underlined the role of the human capital accumulation technology and the nature of the leisure activity in determining the effects of labor, capital and consumption taxes.

It was shown that a consumption tax involves only one fundamental distortion -- it affects the choice between time spent in "productive" activities (labor and education) and in leisure time in favor of the latter, and therefore reduces the growth rate of the economy. This choice is affected in a similar fashion by income taxes, but the latter taxes also involve other distortions that reduce capital accumulation and growth. This suggests that an optimal taxation plan would feature heavier reliance on consumption taxes than on income taxes in the transition to the balanced growth path. However, we have shown that the solution to the optimal taxation problem when the government can freely borrow and lend features

\footnotetext{
${ }^{21}$ These are estimates of the ad-valorem tax rates that represent the wedges distorting optimal plans in a macroeconomic, representative agent setting. They are constructed by comparing measures of aggregate post- and pre-tax incomes and prices.
} 
zero taxation of factor income and consumption in the long run. This result is in contrast with those obtained in neoclassical exogenous growth models, where consumption taxes are welfare-superior to capital income taxes. The result that all long-run taxes should be zero is clearly unrealistic and suggests the necessity to re-examine dynamic optimal taxation subject to a more realistic set of restrictions on government's behavior. Further insights can be gained by explicitly introducing heterogeneity among economic agents, in order to address distributional considerations. ${ }^{22}$

2 See, for example, Garcia-Milà, Marcet and Ventura (1995). 


\section{APPENDIX}

\section{A1. Derivation of long-run equilibrium conditions}

The first-order conditions can be expressed as follows:

$$
\begin{gathered}
e^{-\beta t} C_{t}^{-\theta}\left(1-u_{t}-z_{t}\right)^{\eta(1-\theta)}=\lambda_{t}\left(1+\tau_{t}^{c}\right) \\
-\frac{\dot{\lambda}_{t}}{\lambda_{t}}=r_{t}=R_{t}^{K}\left(1-\tau_{t}^{K}\right)-\delta \\
-\frac{\dot{\mu}_{t}}{\mu_{t}}=(1-\beta) B\left(\frac{\left(1-v_{t}\right) K_{t}}{z_{t} H_{t}}\right]^{\beta}\left(u_{t}+z_{t}\right)-\delta \\
R_{t}^{H}\left(1-\tau_{t}^{H}\right) H_{t}=\frac{\eta\left(1+\tau_{t}^{c}\right)}{1-u_{t}-z_{t}} C_{t} \\
\lambda_{t} R_{t}^{K}\left(1-\tau_{t}^{K}\right)=\mu_{t} B \beta\left[\frac{\left(1-v_{t}\right) K_{t}}{z_{t} H_{t}}\right]^{\beta-1} \\
\lambda_{t} \eta \frac{C_{t}\left(1+\tau_{t}^{C}\right)}{1-u_{t}-z_{t}}=\mu_{t}(1-\beta) B H_{t}\left[\frac{\left(1-v_{t}\right) K_{t}}{z_{t} H_{t}}\right]^{\beta}
\end{gathered}
$$

The remaining two first order conditions (FOCs) are the constraints (2) and (12). Equation (A1) states that the shadow price of consumption (physical capital) must equal the marginal utility of consumption in every period. Equation (A2) is the FOC for capital accumulation: the rate of change of the shadow price of consumption must equal the marginal product of capital net of tax, which must also equal the rate of return on government bonds. Together with equation (10), this determines equation (14) in the text. Equation (A3) is the corresponding FOC for human capital accumulation, relating the change in the shadow price of human capital to its marginal rate of return. Equation (A4) equates the marginal rate 
of substitution between consumption and leisure to the real wage. Together with equation (11), it determines equation (18) in the text. Equation (A5) describes the optimal allocation of capital between production and education, and equation (A6) the optimal allocation of time between education and leisure.

The transversality conditions are:

$$
\begin{aligned}
& \lim _{t \rightarrow \infty} \lambda_{t} K_{t}=0 \\
& \lim _{t \rightarrow \infty} \mu_{t} H_{t}=0
\end{aligned}
$$

From (A4), (A5) and (A6) it is straightforward to obtain

$$
R^{K}\left(1-\tau^{K}\right) K=R_{t}^{H}\left(1-\tau^{H}\right) H \frac{\beta}{1-\beta} \frac{z}{1-v}
$$

which, together with the firms' FOCs (10) and (11) yields equation (16) in the text. Log-differentiating (13) and using the fact that factor allocations are constant along the balanced growth path, we obtain:

$$
\frac{C}{C}=-\frac{1}{\theta}\left(\rho+\frac{\dot{\lambda}}{\lambda}\right)
$$

where time subscripts have been omitted. Along the balanced growth path, the shadow prices of physical and human capital must decline at the same rate. Equating (2) and (A3) we determine equation (15) in the text. Using (A2) and (A9) we obtain an expression for the balanced growth rate of the economy (equation (11)). Equation (17) in the text is obtained by equating the growth rate in human capital (see equation (2)) to the balanced growth rate of the economy.

\section{A.2 Proof of Propositions (1) and (3)}

The proof follows Devereux and Love (1994). Using equations (13), (15) and (17), it is possible to express the share of time spent working as follows:

$$
z=\xi(u+z)
$$

where 


$$
\xi=(1-\beta) \frac{\gamma+\delta}{\theta \gamma+\delta+\rho}
$$

We can then use (A10) together with equations (14), (16), (18) and (19) to determine a relation between the time spent working or studying $u+z$ and the rate of growth through the variable $\xi$ :

$$
u+z=\frac{1}{1+\frac{1+\tau^{C}}{1-\tau^{H}} \frac{\eta(1-\xi)}{1-\alpha}\left[1-g-\frac{\xi}{(1-\xi)(1-\beta)^{2}}\left[\alpha(1-\beta)(1-\xi)\left(1-\tau^{X}\right)+(1-\alpha) \beta \xi\left(1-\tau^{H}\right)\right]\right]}
$$

where the term in brackets beginning with $1-g$ is the share of consumption in total output. This relation and the semi-reduced form for the growth rate (19) determine the values of $\gamma$ and $u+z$. It is easy to check that equation (A12) is monotonically decreasing in $\xi$ : therefore, the relation between $u+z$ and $\gamma$ identified by this relation depends crucially on the sign of $\xi^{\prime}(\gamma)$.

In order to determine the effects of taxes on economic growth, it is useful to plot the schedules (19) and (A12) in $(\gamma, u+z)$ space. The first schedule is upward sloping and monotonically increasing. The second schedule could be upward or downward sloping, depending on the sign of $\xi^{\prime}(\gamma)$. In the former case, the schedule is always below one, and therefore has to intersect the first schedule from above. An increase in the consumption tax shifts the second schedule downwards, irrespectively of its slope, while leaving the first unaffected. This unambiguously reduces growth and $u+z$, thus proving Proposition 3. An increase in the tax on human or physical capital shifts both schedules: the first one upwards and the second one downwards. Both shifts reduce the growth rate, thus proving Proposition 1. Note that the time spent working or studying is always reduced when the second schedule is upwardsloping, while its sign is uncertain when it is downward-sloping.

When leisure is a market good, equations (A11) and (A12) become: 


$$
\begin{gathered}
\xi=(1-\beta)\left(1-\tau^{H}\right) \frac{\gamma+\delta}{\theta \gamma+\delta+\rho} \\
u+z=\frac{1}{1+\frac{1+\tau^{C}}{1-\tau^{H}} \frac{\eta(1-\xi)}{1-\alpha}\left[1-g-\frac{\xi\left(1-\tau^{K}\right)}{(1-\xi)(1-\beta)^{2}}[\alpha(1-\beta)(1-\xi)+(1-\alpha) \beta \xi]\right]}
\end{gathered}
$$

The qualitative effects of taxes on growth are the same as those discussed for the case above.

\section{A3. Optimal taxation when leisure is "raw time"}

In this Appendix we prove formally the optimality of zero long-run taxes on both human and physical capital for a model in which leisure takes the form of raw time. The first step consists in expressing the consumer's intertemporal budget constraint (IBC) as a function of quantities only. By integrating forward the instantaneous consumer budget constraint (12) and imposing the transversality condition (A7) and the no-Ponzi game condition, we obtain the following intertemporal budget constraint:

$$
\int_{0}^{\infty} e^{-\int r_{s} d z}\left[C_{t}\left(1+\tau_{t}^{C}\right)+\left(1-v_{t}\right) R_{t}^{K}\left(1-\tau_{t}^{K}\right) K_{t}-u_{t} R_{t}^{H}\left(1-\tau_{t}^{H}\right) H_{t}\right] d t=K_{0}
$$

where $r$ is defined as in (14) and initial debt $B_{o}$ has been assumed to be zero without loss of generality. Integrating the first-order condition (A2) between zero and $t$ and using the F.O.C. for consumption (A1) we get:

$$
\frac{\lambda_{t}}{\lambda_{0}}=e^{-\int_{o^{1}}^{1}\left[R_{t}^{x_{0}}\left(1-\tau_{t}^{x}\right)-\delta\right] d z}=e^{-\rho t}\left[\frac{C_{t}}{C_{0}}\right]^{-\theta}\left[\frac{l_{t}}{l_{0}}\right]^{\epsilon(1-\theta)} \frac{1+\tau_{0}^{c}}{1+\tau_{t}^{C}}
$$

The differential equations for human capital accumulation (2) and its shadow price (A3) can be integrated forward to determine the value of the representative agent's human wealth. Using equations (A1) and (A4)-(A6) human wealth can be expressed as follows: 


$$
\mu_{0} H_{0}=\int_{0}^{\infty} \lambda_{s}\left[R_{s}^{H}\left(1-\tau_{s}^{H}\right) H_{s}\left[u_{s}-\frac{\beta}{1-\beta} z_{s}\right]\right] d s
$$

Adding (A15) and (A17) and using (A8) to express $R^{K}$ as a function of $R^{H}$ the consumer's IBC becomes:

$$
\int_{0}^{\infty} \lambda_{t} C_{t}\left(1+\tau_{t}^{c}\right) d t=\lambda_{0} K_{0}+\mu_{0} H_{0}
$$

Equation (A18) simply states that the PDV of consumption -- its level times its price $\lambda\left(1+\tau^{\mathrm{C}}\right)-$ has to be equal to the value of the representative agent's total wealth. This is an "implementability constraint" that the government's optimal plan needs to satisfy. Using (A16) to substitute for $\lambda_{1}$ and $\lambda_{0}$; and substituting for $\mu_{0}$ from the consumer's FOCs, we can re-write (A18) as follows:

$$
\int_{0}^{\infty} e^{-\rho t}\left(C_{t} l_{t}^{\epsilon}\right)^{1-\theta} d t=\hat{W}_{0}
$$

where $\hat{W}_{0}$ depends only on time zero variables, and is given by:

$$
\hat{W}_{0}=C_{0}^{1-\theta} l_{0}^{\eta(1-\theta)}\left[\frac{K_{0}}{\left(1+\tau_{0}^{c}\right) C_{0}}+\frac{1}{(1-\beta) B} \frac{\epsilon}{1-u_{0}-z_{0}}\left[\frac{\left(1-v_{0}\right) K_{0}}{z_{0} H_{0}}\right]^{-\beta}\right]
$$

The last constraint we need to impose on the behavior of the government concerns the process of human capital accumulation.

Equations (2) and (A12) determine a constraint associated with human capital accumulation:

$$
R_{t}^{H}\left(1-\tau_{t}^{H}\right) H_{t}=(1-\beta) B\left[\frac{x_{t} K_{t}}{z_{t} H_{t}}\right]^{\beta} \int_{t}^{\infty} e^{\int_{t}^{r_{2} d z}} R_{s}^{H}\left(1-\tau_{s}^{H}\right) H_{s}\left(u_{s}-\frac{\beta}{1-\beta} z_{s}\right) d s
$$

The LHS of this expression is the gain for the consumer if she increases marginally her labor supply $u_{t}$. This must be equal to the resources the consumer would have had by devoting one more unit to the 
accumulation of human capital (RHS). These resources include the additional income from time spent producing market goods $\left(u_{i}\right)$, as well as a term with a minus sign that represents the negative effect on the MPK of devoting less time to education. Using (A4) and (A7) the constraint (A21) can be written as:

$$
e^{-\rho t}\left(C_{t} L_{t}^{t}\right)^{1-\theta}=\left(1-u_{t}-z_{t}\right) B\left(\frac{\left(1-v_{t}\right) K_{t}}{z_{t} H_{t}}\right]^{\beta} \int_{t}^{\infty} e^{-\rho s}\left(C_{s} l_{s}^{t}\right)^{1-\theta} \frac{u-\beta /(1-\beta) z_{s}}{1-u_{s}-z_{s}} d s
$$

The government's restricted Ramsey plan consists in maximizing consumer's utility subject to the economy's resource constraint (4); the human capital "production" technology (2); the implementability constraint (A15); and the human capital accumulation constraint (A22). Let $\psi$ be the Lagrange multiplier associated with the implementability constraint, and define $W_{t}=(1+\Psi)(1+\theta)^{-1}\left(C l_{t}^{\eta}\right)^{1-\theta}$. It is easy to see that the planner's problem can be re-formulated as follows:

$$
\operatorname{Max} \int_{0}^{\infty} e^{-\rho t} W_{t} d t-\psi \hat{W}_{0}
$$

subject to the constraints (4), (2), (A15) and (A22) to which we associate the multipliers $\lambda_{t}, \mu_{t}$ and $\phi_{t}$ respectively. Let $\sigma=x K / z H$ and $\varpi=v K / u H$ along the balanced growth path, and define $s^{*}$ as the value of the variable s, discounted by its long-run growth rate, along the balanced growth path. The first-order conditions, evaluated along the balanced growth path, can be expressed as follows:

$$
\begin{gathered}
\lambda^{*}=\hat{W}_{c}^{*}\left[1+\phi^{*}\left[1-(1-\beta) B \sigma^{\beta}\left(u-\frac{\beta}{1-\beta} z\right)\right]\right] \\
-\frac{\dot{\lambda}}{\lambda}=\alpha A \omega^{\alpha-1}-\delta \\
-\frac{\dot{\mu}}{\mu}=(1-\beta) B\left(u^{*}+z^{*}\right) \sigma^{\beta}-\delta+\frac{\phi}{\mu} \frac{W^{*}}{H^{*}}\left[u B \sigma^{\beta} \frac{1-\beta u^{*}-z^{*}}{1-u^{*}-z^{*}}+\beta\left(1+\frac{u^{*}}{z^{*}}\right)\right]
\end{gathered}
$$




$$
\begin{gathered}
\lambda^{*} \alpha A K^{*} \omega^{\alpha-1}\left[1-\frac{1-\alpha}{\alpha} \frac{\beta}{1-\beta} \frac{z^{*}}{1-v^{*}} \frac{v^{*}}{u^{*}}\right]=-\phi^{*} \frac{\hat{W}^{*}}{1-v^{*}} \frac{\beta}{1-\beta}\left[1+B z^{*} \sigma^{\beta} \frac{1-\beta u^{*}-z^{*}(A 27)}{1-u^{*}-z^{*}}\right] \\
\lambda^{*}\left[\frac{\epsilon C^{*}}{\left(1-u^{*}-z^{*}\right)}-(1-\alpha) H^{*} \omega^{\alpha}\right]=\frac{\phi^{*} W^{*}}{1-u^{*}-z^{*}}\left[1-\left(1-\beta-z^{*}\right) B \sigma^{\beta}\right]
\end{gathered}
$$

Comparing these FOC with those of the consumer problem along the balanced growth path, it is immediate from (A2) and (A30) that the long-run tax rate on capital has to be zero. Because of the equality between the rate of change of $\lambda$ and $\mu$ along the balanced growth path, equation (A26) together with (A3) implies that $\phi^{*}$ is equal to zero. This also implies that the LHS of equation (A27) is equal to zero, proving that $\tau^{H}$ is equal to zero (compare with equation (16)). Finally, the term in square brackets on the LHS of equation (A28) has to be equal to zero, implying that the tax on consumption $\tau^{c}$ has to be zero as well in the long run (compare with equation (A4)). The intuition for the fact that the constraint imposed by the consumer's optimality conditions on the government's behavior is not binding in the long run $\left(\phi^{*}=0\right)$ is the following. In the long run, $\tau^{K}=\tau^{H}=\tau^{C}=0$ : hence all distortions are eliminated and the consumer's optimality constraints do not restrict the government's resource allocation choice.

The proof for the case in which leisure is home production or quality time can be constructed in an analogous fashion, and is available from the authors. 


\section{BIBLIOGRAPHY}

Atkinson, Anthony and Agnar Sandmo (1980), "Welfare Implications of the Taxation of Savings", Economic Journal 90, 529-49.

Auerbach, Alan and Lawrence Kotlikoff (1987), Dynamic Fiscal Policy, Cambridge: Cambridge University Press. Auerbach, Alan, Lawrence Kotlikoff and Jonathan Skinner (1983), "The Efficiency Gains from Dynamic Tax Reform", International Economic Review 24, 81-100.

Barro, Robert (1990), "Government Spending in a Simple Model of Endogenous Growth", Journal of Political Economy 98, part 2, October, S103-S125.

Barro, Robert and Xavier Sala-i-Martin (1994), Economic Growth, New York: Mc Graw-Hill.

Becker, Gary S. (1965), "A Theory of the Allocation of Time", Economic Journal 75, September, 493-517.

Benhabib, Jess, Richard Rogerson and Randall Wright (1991), "Homework in Macroeconomics: Household Production and Aggregate Fluctuations", Journal of Political Economy 99, December 1991, 1166-87.

Ben Porath, Yoram (1967), "The Production of Human Capital and the Life-Cycle of Earnings", Journal of Political Economy 75, No.4 part 1, August, 352-365.

Boskin, Michael J. (1978), "Taxation, Saving and the Rate of Interest", Journal of Political Economy 86, April, S3-27.

Bull, Nicholas (1993), "When All the Optimal Dynamic Taxes Are Zero", Federal Reserve Board Working Paper no. 137 , July.

Caballe, Jordi and Manuel S. Santos (1993), "On Endogenous Growth with Physical and Human Capital", Journal of Political Economy 101, December, 1042-67.

Chamley, Christophe (1985), "Efficient Taxation in a Stylized Model of Intertemporal General Equilibrium", International Economic Review 26, No.2, June, 451-468.

Chamley, Christophe (1986), Optimal Taxation of Capital Income in General Equilibrium with Infinite Lives", Econometrica 54, May, 607-22. 
Chari, V.V., Lawrence J. Christiano and Patrick J. Kehoe (1991), "Optimal Monetary and Fiscal Policy in a Business Cycle Model", Journal of Money, Credit and Banking 23, August (part 2), 519-39.

Chari, V.V., Lawrence J. Christiano and Patrick J. Kehoe (1994), "Optimal Fiscal Policy in a Business Cycle Model", Journal of Political Economy 102, August, 617-52.

Devereux, Michael B. and David R. Love (1994), "The Effects of Factor Income Taxation in a Two-Sector Model of Endogenous Growth", Canadian Journal of Economics XXVII, August, 509-36.

Devereux, Michael B. and David R. Love (1995), "The Dynamic Effects of Government Spending Policies in a Two-Sector Endogenous Growth Model", Journal of Money, Credit and Banking 27, February, 232-56.

Easterly, William and Sergio Rebelo (1993a), "Marginal income tax rates and economic growth in developing countries," European Economic Review 37, 409-417.

Easterly, William and Sergio Rebelo (1993b), "Fiscal policy and economic growth: an empirical investigation," Journal of Monetary Economics 32, 417-458.

Engen, Eric and Jonathan Skinner (1992), "Fiscal Policy and Economic Growth", NBER Working Paper no. 4223, December.

Feldstein, Martin (1978), "The Welfare Cost of Capital Income Taxation", Journal of Political Economy 86, April, S29-51.

Fullerton, D., J. B. Shoven and T. Whalley (1983), "Replacing the US Income Tax with a Progressive Consumption Tax", Journal of Public Economics 20, 2-23.

Garcia-Milà, Teresa, Albert Marcet and Eva Ventura (1995), "Supply Side Intervention and Redistribution", Universitat Pompeu Fabra Working Paper no. 115, June.

Greenwood, Jeremy and Zvi Hercowitz (1991), "The Allocation of Capital and Time over the Business Cycle", Journal of Political Economy 99, December, 1188-1214.

Heckman, James (1976), "A Life-Cycle Model of Earnings, Learning, and Consumption", Journal of Political Economy 84, August, S11-S44. 
Jones, Larry E., Rodolfo E. Manuelli and Peter E. Rossi (1993a), "Optimal Taxation in Models of Endogenous

Growth", Journal of Political Economy 101, June, 485-517.

Jones, Larry E., Rodolfo E. Manuelli and Peter E. Rossi (1993b), "On the Optimal Taxation of Capital Income", NBER Working Paper no. 4525, November.

Judd, Kenneth L. (1985), "Redistributive Taxation in a Simple Perfect Foresight Model", Journal of Public Economics 28, October, 59-83.

Judd, Kenneth L. (1987), "The Welfare Cost of Factor Taxation in a Perfect Foresight Model", Journal of Political Economy 95, No.4, 675-709.

Judd, Kenneth L. (1990), "Optimal Taxation in Dynamic Stochastic Economies", mimeo, Stanford University. Kay, John (1989), "Consumption Taxation", in J. Eatwell and M. Milgate (eds., The Palgrave Dictionary, $617-$ 18.

Kaldor, Nicholas (1955), An Expenditure Tax, London: Allen and Unwin.

Kim, Se-Jik (1992) Taxes, Growth and Welfare in an Endogenous Growth Model, Ph.D. Dissertation, University of Chicago.

King, Mervyn (1980), "Savings and Taxation", in G. M. Heal and G. A. Hughes (eds.), Public Policy and the Tax System, London: Allen and Unwin.

King, Robert G. (1991), "Observable Implications of Dynamically Optimal Taxation", University of Rochester Working Paper, August.

King, Robert G., Charles I. Plosser and Sergio T. Rebelo (1988), "Production, Growth and Business Cycles: I. The Basic Neoclassical Model", Journal of Monetary Economics 21, 195-232.

King, Robert G. and Sergio Rebelo (1990), "Public Policy and Economics Growth: Developing Neoclassical Implications", Journal of Political Economy 98, No.5, part 2, October, S126-S150.

Koester, R. and R. Kormendi, (1989), "Taxation, Aggregate Activity and Economic Growth: Cross-Country Evidence on Some Supply-Side Hypotheses," Economic Inquiry 27, 367-386. 
Lucas, Robert E. Jr. (1988), "On the Mechanics of Economic Development", Journal of Monetary Economics $22,3-42$.

Lucas, Robert E. Jr. (1990), "Supply-Side Economics: an Analytical Review", Oxford Economic Papers 42, 293-316.

Lucas, Robert E. Jr. and Nancy L. Stokey (1983), "Optimal Monetary and Fiscal Policy in an Economy without Capital", Journal of Monetary Economics 12, July, 55-93.

Mendoza, Enrique G., Gian Maria Milesi-Ferretti and Patrick Asea (1995), "Do Taxes Matter for Long Run Growth? Harberger's Superneutrality Conjecture", IMF Working Paper no. 95/79, June.

Mendoza, Enrique G., Assaf Razin and Linda L. Tesar (1994) "Effective Tax Rates in Macroeconomics: CrossCountry Estimates of Tax Rates on Factor Incomes and Consumption," Journal of Monetary Economics, vol. $34,297-323$.

Milesi-Ferretti, Gian Maria and Nouriel Roubini (1994a), "Optimal Taxation of Human and Physical Capital in Endogenous Growth Models", NBER Working Paper no. 4882, October.

Milesi-Ferretti, Gian Maria and Nouriel Roubini (1994b), "Taxation and Growth in Open Economies", NBER Working Paper no. 4881, October.

Mill, John Stuart (1848), Principles of Political Economy with some of their Applications to Social Philosophy, in Collected Works of John Stuart Mill, ed. by J. M. Robson, Toronto: University of Toronto Press, 1965 .

Mulligan, Casey and Xavier Sala-i-Martin (1993), "Transitional Dynamics in Two-Sector Models of Endogenous Growth", Quarterly Journal of Economics CVIII, August, 739-73.

Pecorino, Paul (1993), "Tax Structure and Growth in a Model with Human Capital", Journal of Public Economics 52, 251-71.

Rebelo, Sergio (1991), Long-Run Policy Analysis and Long-Run Growth", Journal of Political Economy 99, June, 500-521. 
Romer, Paul (1986), "Increasing Returns and Long-Run Growth", Journal of Political Economy 94, October, 1002-1037.

Slemrod, Joel (1990), "Optimal Taxation and Optimal Tax Systems", Journal of Economic Perspectives 4, Winter, 157-78.

Stern, Nicholas (1992), "From the Static to the Dynamic: Some Problems in the Theory of Taxation", Journal of Public Economics 47, March, 273-97.

Stokey, Nancy L. and Sergio Rebelo (1995), "Growth Effects of Flat-Rate Taxes", Journal of Political Economy 103, June, 419-50.

Summers, Lawrence H. (1981), "Capital Taxation and Accumulation in a Life-Cycle Growth Model", American Economic Review 71, September, 533-44.

Tanzi, Vito and Howell H. Zee (1993), "Time Constraint in Consumption and Savings Behavior", Journal of Public Economics 50, 253-259.

Trostel, Phillip (1993), "The Effect of Taxation on Human Capital", Journal of Political Economy 101, April, 327-50.

Yuen, Chi-Wa (1990), "Taxation, Human Capital Accumulation and Economic Growth", mimeo, University of Chicago. 